\title{
Study on Disassembly Scheme of Large Diameter Shield Machine
}

\author{
Xin $\mathrm{Li}^{1,2, a}$, Jianhua $\mathrm{Hu}^{1,2, b}$, Jiping $\mathrm{Liu}^{3, \mathrm{c}}$ \\ ${ }^{1}$ School of Materials Science and Engineering ,Wuhan University of Technology, Wuhan 430070, \\ China \\ ${ }^{2}$ State Key Laboratory of Material Processing and Die\&Mould Technology, Huazhong University of \\ Science and Technology, Wuhan 430074, China \\ ${ }^{3}$ China Railway Science and Industry Group Rail Transportation Equipment Limited Company, \\ Wuhan 430200, China



Key Words: Shield machine, Cutter head, Finite element simulation, Stress-strain

Abstract: In view of the special situation that the shield machine cannot be removed from the tunnel when meets the cutter head, and it must be decomposed and disassembled before it can be taken out in blocks, needing to construct the three-dimensional model of the cutter head, and the structural statics finite element simulation of the three dimensional model of the cutter head under normal working condition and $1 / 3$ radius plugging condition is carried out by using the relevant software, and the stress-strain law of the cutter head under these two conditions is analyzed. Based on the analysis of the structure of the cutter head, the core position of the cutter head, the degree of difficulty in recovery and the size of the block, a reasonable dis-assembly scheme for the cutter head of the large diameter shield machine is designed.

\section{Introduction}

With the continuous development of society and economy, the ground transportation can not meet the needs of human beings now. The underground space has become the object of the next development of human beings, and the shield machine with the name "underground giant beast" has also developed. As a safe, fast, efficient, and environmentally-friendly form of transportation, urban subway has quickly become the primary choice for solving traffic problems in many large cities ${ }^{[1,2]}$. As one of the most important components of the shield machine, the cutter head has been rapidly developed since its appearance. The cutter head can be divided into spoke-type cutter head, panel-type cutter head, compound cutter head ${ }^{[3,4]}$. Geological investigation plays an important role in the selection and design of shield cutter head, but in the actual construction process, there will be more severe geological environment and working conditions, which will cause great damage to the cutter head of shield machine. Due to the problems in the previous geological exploration, the choice and design of the cutter head of the shield machine are unreasonable. The cutter head of the shield machine has many problems during the construction of the tunnel, which leads to the delay in the construction period. In addition, due to the existence of subway stations and other buildings above the tunnel, it is not possible to excavate large diameter shafts. Therefore, the cutter head cannot be taken out of the tunnel shaft as a whole. Due to the harsh geological environment, the cutter plate is corroded and damaged seriously, so it cannot be disassembled according to the original method. After the disassembly of the cutter, it needs to be welded and restored, and the 
weld should avoid the concentrated stress and strain area as far as possible. In order to simplify the process of the cutter head recovery and ensure the mechanical properties of the reformed cutter head, in this paper, the stress and strain analysis of the cutter head under different working conditions is carried out by using the relevant software. Combined with the structure analysis of cutter head and the result of the finite element simulation, a disassembly scheme for large diameter shield cutter head is designed.

\section{Cutter head and 3D model}

The shield machine is an articulated earth pressure balance shield machine with a cutter head diameter of $8.8 \mathrm{~m}$. Due to the cutter head of the shield machine is welded structure. If the welded structure model of the cutter head is used as a three-dimensional model for the finite element simulation, it will cause difficulties in finite element simulation. In order to solve this problem, we use Solidworks software to build a holistic the cutter head model, the final model of the cutter head is a solid part. In order to simplify the calculation process and increase the finite element analysis rate, the cutter head model is now simplified as follows:

(1) Remove all housings and cutters;

(2) Simplify some parts of the circular chamfer and foam holes on the cutter head;

(3) The material properties of the weld are the same as the material properties of the adjacent components ${ }^{[5,6]}$.

The quality of the mesh directly affects the calculation speed and the accuracy of the results of finite element analysis ${ }^{[7]}$. Due to the complex structure and large size of the cutter head, tetrahedral meshing is used to mesh 3D model of the cutter head. There are 625585 nodes and 338787 units in the cutter head model after meshing. The simplified cutter head 3D model and meshing model are shown in Fig. 1 and Fig. 2



(a) tunnel face



(b) flange face

Fig. 1 Three-dimensional model of cutter head 




Fig. 2 Finite element mesh division model of cutter head

\section{Main parameters, working load and boundary conditions}

The cutter head is a $8.8 \mathrm{~m}$ composite cutter head with an opening ratio of $36 \%$. The material of the cutter head is Q345 steel, the density is $7850 \mathrm{~kg} / \mathrm{m}^{3}$, the elastic modulus is $206 \mathrm{GPa}$, and the Poisson's ratio is 0.28 . During the tunneling process of the shield machine, the cutter head is mainly subjected to propulsion resistance and cutting resistance. Due to the slow speed of advancement and rotation of the shield machine, it is possible to simulate the stress and strain of shield cutter head under normal working condition and $1 / 3$ radius plugging condition by using structural statics ${ }^{[8]}$. The force received by the cutter is evenly distributed to the tunnel face of the cutter head. Therefore, thrust and torque are applied to the tunnel face and the outer ring of the cutter head, and the bottom of the flange is fully constrained.

Normal working condition. Under the condition of normal working, the thrust of the cutter head is $4 \times 10^{7} \mathrm{~N}$, and the rated torque is $1.49 \times 10^{7} \mathrm{~N} \cdot \mathrm{m}$. The thrust and the torque are loaded on the tunneling face and the outer ring of the cutter head. The bottom of the flange is fully constrained, and the influence of the cutter head' weight is considered. The results of the finite element simulation are as follows:



(a) tunnel face



(b) flange face

Fig. 3 Stress nephogram under normal working conditions 




(a) tunnel face



(b) flange face

Fig. 4 Strain nephogram under normal conditions

The maximum stress of the cutter head under normal working conditions is $172.68 \mathrm{MPa}$, which occurs at the welding point of the flange and corbel parts of the cutter head. The safety factor is 1.99, which meets the requirements of the cutter head's material. The maximum deformation of the cutter head is $2.1 \mathrm{~mm}$ and it appears on the outer ring of the cutter head.

1/3 radius plugging condition. $1 / 3$ radius plugging condition usually occurs in the hard rock tunneling process. The reason for this condition is that the rock is accumulated on the front side of the cutter head due to the excessive speed of the shield or the collapse of the front cutting surface, which causes the cutting torque of the cutter head to be insufficient to overcome the frictional resistance and stop. Usually, when the rock and soil accumulation height reaches a third of the radius of the cutter head, the cutter head stops, so it is generally referred to as a $1 / 3$ radius plugging condition $^{[9]}$. As shown in Fig. 5, assuming that the friction force on the tunneling face of the cutter head is $\mathrm{f}$, the area of the action is A, and the distance from each point on the action surface to the rotation axis is $r$, then there are:

$$
\int_{A}^{f} \frac{f}{A} d A \cdot r=T \text {. }
$$

Where:

$$
d A=\theta r \times d r=2 r \cos ^{-1}\left(\frac{2 R}{3 r}\right) d r
$$

Then:

$$
T=\int_{\frac{2 R}{3}}^{R} \frac{f}{A} d A r .
$$

Equations (1), (2) and (3) imply:

$$
f=\frac{T A}{\int_{\frac{2 R}{3}}^{R} r^{2} \cos ^{-1}\left(\frac{2 R}{3 r}\right) d r} \text {. }
$$

It can be seen from the equation (4) that the friction force $\mathrm{f}$ is difficult to solve. Assuming that the focal force at the contact center of the third-third radius of the contact surface is the friction 
force $\mathrm{f}$, the distance from the center of the centroid to the center of rotation of the cutter head can be obtained as L1 $=3530 \mathrm{~mm}$. According to the principle of moment balance, it can be obtained:

$$
\mathrm{T}_{\mathrm{R}}=\mathrm{f} \times \mathrm{L}_{1} .
$$

Where $T_{R}$ is rated torque of the shield machine, and then:

$$
\mathrm{f}=\frac{\mathrm{T}_{\mathrm{R}}}{\mathrm{L}_{1}}=\frac{1.49 \times 10^{10}}{3530} \mathrm{~N}=4.22 \times 10^{6} \mathrm{~N}
$$

The coefficient of friction between steel and rock is $\mu=0.33$, then the thrust of the cutter head under $1 / 3$ radius plugging condition is:

$$
F=\frac{f}{\mu}=\frac{4.22 \times 10^{6}}{0.33}=1.28 \times 10^{7} \mathrm{~N}
$$



Fig. 5 Stress Analysis of 1/3 radius plugging condition

Under this condition, the thrust force at the contact surface of one-third radius of the cutter head is $1.28 \times 10^{7} \mathrm{~N}$, and the rated torque is $1.49 \times 10^{7} \mathrm{~N} \cdot \mathrm{m}$. The bottom surface of the flange is fully constrained, and the influence of the self-weight of the cutter head is considered. Finite element simulation results are as follows.



(a) tunnel face



(b) flange face

Fig. 6 Stress nephogram under $1 / 3$ radius plugging condition 


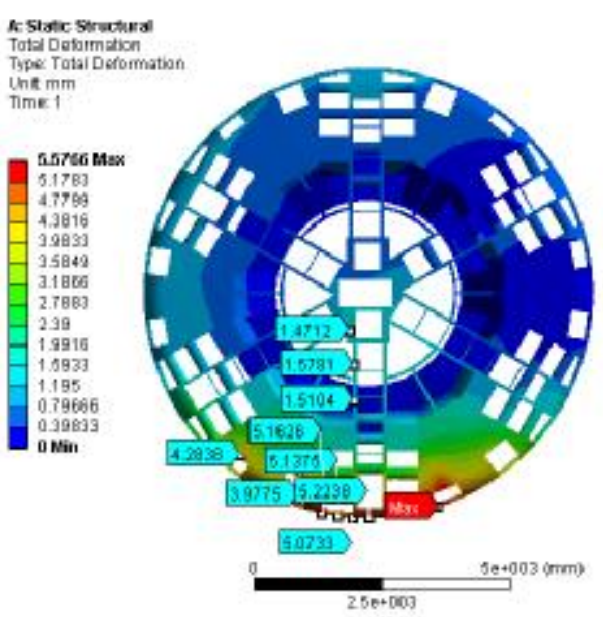

(a) tunnel face

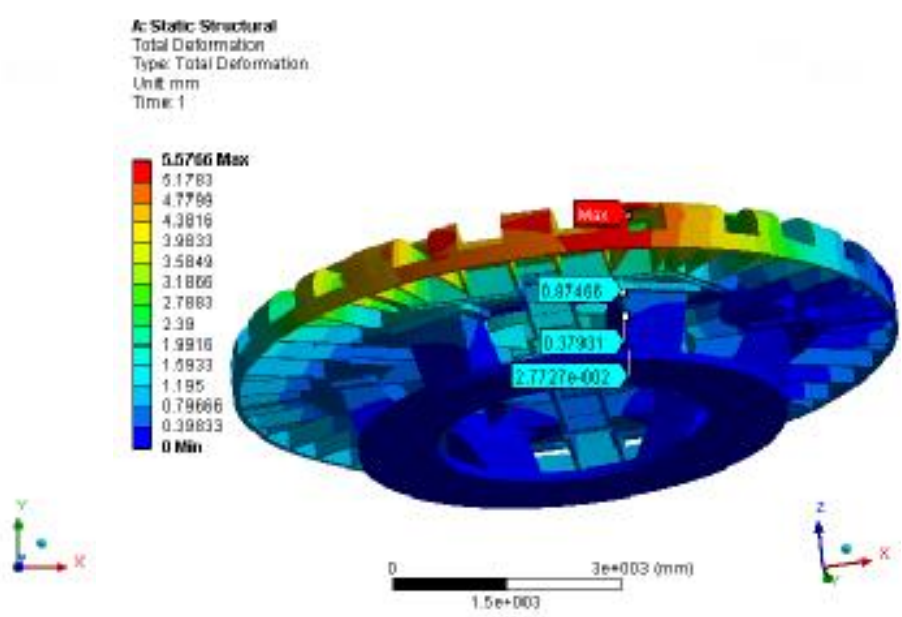

(b) flange face

Fig. 7 Strain nephogram under 1/3 radius plugging condition

Under this working condition, the maximum stress of the cutter head is $318.9 \mathrm{MPa}$, which occurs at the welding point of the flange and corbel parts of the cutter head. It is already close to the allowable stress of the cutter head's material. Therefore, the maximum stress parts of the corbel part are refined locally, and the results of finite element simulation show that the maximum stress increases with the increase of mesh refinement, which is a typical stress concentration phenomenon. Due to the stress on the corbel of the cutter head is continuous and progressive, the linear extrapolation method can be used to calculate the exact maximum stress value. In order to obtain the true maximum stress value of the cutter head, it is necessary to set the path on the corbel to simulate the analysis of the variation law of stress along path 1 to 2 and take the point before the stress mutation to perform linear fitting. The results of simulation and calculation are as follows:



Fig. 8 Scatter plot of stress data on the corbel



Fig. 9 The scatter plot of linear extrapolation

From the simulation results in Fig. 8, it can be seen that stress mutations occurred at the corbel of the cutter head at $198.25 \mathrm{~mm}$. Selecting the stress data before the mutation point for linear extrapolation analysis, the linear equation for the stress is shown in Fig. 9. The linear equation is $y=0.2468 x+165.18$, the correlation degree is as high as 0.9995 . The maximum stress at the corbel can be obtained by bringing the maximum stress point $(x=198.25 \mathrm{~mm})$ into the linear equation, which is $238.57 \mathrm{MPa}$. The safety factor is 1.45 . Even if the cutter head is locked in a $1 / 3$ radius plugging condition, the material and structure of the cutter head meet the design requirements too. 


\section{Analysis of Disassembly Scheme}

The Disassembly Scheme of the corbel. According to the simulation results of Figure 3 and Figure 6 , the stress of the cutting surface 3 and the cutting surface 2 is larger, and the stress at the 1 section of the cutting surface is slightly smaller. If the cutting surface 1 is disassembled, the structure of the flange will be destroyed. The flange plate is connected with the rotating shaft of the shield machine, which is the core part of the cutter head. It is difficult to ensure the concentricity of the flange and the outer ring of the cutter head during the welding repair too. However, if the cutting surface 2 is disassembled, it will be difficult to ensure the parallelism between the flange plate and the cutter head when the cutter head is welded and repaired, and the steel plate above the cutting surface 2 needs to be removed to add a new steel plate for welding, which will result in the complexity of the welding repair process and the increase of the repair cost. Although the stress on the cutting surface 1 is large, the maximum stress is far less than the allowable stress of the cutter head. Compared to the cutting surfaces 1 and 2, the cutting surface 3 is less expensive and the process is simpler. In addition, the board of the corbel is thicker. In the welding repair process, the strength can be improved by selecting a reasonable welding process scheme or adding a rib to the cutting surface 3 . Considering all factors, the cutting surface 3 is selected as the disassembly scheme of the corbel, the model of cutter head after cutting is shown in Fig. 11.



Fig. 10 The cutting plan of the corbel of the cutter head



Fig. 11 Three dimensional segmentation model of the corbel part of the cutter head

The disassemble scheme of the outer ring of the cutter head. Due to the structure of the cutter head has symmetry, only the part of its $1 / 6$ is discussed here. According to the simulation results of Figure 3 and Figure 6, it can be seen that the stress at the cutting surface 1 is larger and the stress at the cutting surface 2 is smaller, but both the cutting surface 1 and the cutting surface 2 will break the flange $b$ and other ribs, and the large cross-sectional area after cutting is not conducive to welding repair. From the simulation results, it can be seen that the stress at the cutting surface 3 is greater than the cutting surface 5, and the cutting surface 3 also destroys the flange $b$ of the cutter head. Although the stress and strain on the cutting surface 4 is less than cutting surface 5, it will destroy the multiple knife boxes of the cutter head and increase the difficulty and cost of welding 
repair. The five cutting schemes were analyzed comprehensively, and the cutting surface 5 was selected as the cutting scheme of the outer ring of the cutter head.

According to the "Road Transport Management Methods for Large Objects", the width of the cutter head should be less than $6 \mathrm{~m}$. Combined with the structure of the cutter head, the outer ring of the cutter head can be cut into 3 parts. That is, cutting surface 5 is used as a cutting surface, and $120^{\circ}$ is rotated in sequence to divide the outer ring of cutter head into three parts.



(a) Front



(b) Back

Fig. 12 Cutting scheme of cutter head

The disassemble scheme at the center of the cutter. Due to the center of the cutter head contains multiple cutter boxes, it is the core of the cutter head. Therefore, it must be retained when the cutting scheme is selected. According to the simulation results of Figure 3 and Figure 6 , it can be seen that the stress and strain of the cutting surface A are greater than the cutting surface B. If A is chosen as the cutting surface at the center of the cutter, it will destroy the ribs $\mathrm{C}$ of the cutter head.

Considering the stress distribution and structural characteristics of the cutter head, the cutting surface B is selected to cut the center of the cutter head, and the model of cutter head after cutting is shown in Fig. 14.



Fig. 13 The disassembly scheme at the center of the cutter



Fig. 14 Three dimensional model of cutter head after cutting 


\section{Conclusion}

For the large-diameter shield machine, due to the delay of the construction period, the serious corrosion of the connection part of the cutter head and the building above the tunnel, the larger diameter shaft can not be excavated. Therefore, the cutter cannot be removed from the shaft as a whole. In this paper, the force condition of the cutter head under different working conditions, the structure of the cutter head, the difficulty and the cost of the repair are taken into consideration. The following conclusions are obtained:

(1) In this paper, the finite element analysis software is used to analyze the stress of large diameter shield cutter head under normal working condition and 1/3 radius plugging condition, and the rule of stress and strain under two working conditions is obtained: The maximum position of the stress occurs at the joint between the corbel and the cutter head. The maximum stress is $238.57 \mathrm{MPa}$. The maximum strain position appears on the outer ring of the cutter plate. The maximum deformation is $5.58 \mathrm{~mm}$.

(2) Through the analysis of the structure of the cutter head itself and the difficult degree of welding repair, it can be obtained: It is necessary to keep the center of the cutter head, select the smaller cross-sectional area, retain the flange, avoid cutting the flange $\mathrm{b}$ and the radial ribs $\mathrm{c}$, and the block size meets the "Road Transport Management Methods for Large Objects".

(3) The cutting surface 3 is used as a cutting scheme for the corbel of cutter head, the cutting surface 5 is used as a cutting scheme for the outer ring of the cutter head, and the cutting surface $b$ is used as a cutting scheme for the central part of the cutter head.

\section{Acknowledgements}

This work was financially supported by the National Natural Science Foundation of China (51475345).

\section{References}

[1] M Gu: Development status and prospect of urban rail transit in china[J]. Chinese Railways, Vol. 10(2011), p. 53-56

[2] J.Z Feng: Talking about the construction technology of shield method[J].China New Technologies and Products, Vol. 7(2012), p. 50

[3] M Yang, J Xiong, Z.X Guo et al: Research status of cutter head and cutter in shield machine at home and abroad[J]. Tool Engineering, Vol. 4(2013), p. 8-11

[4] K.Z Song, B.F Wang: Common types of shield cutter wheel and selection[J]. Tunnel Machinery and Construction Technology, Vol. 6(2007), p. 44-46

[5] Y.M Xia, Y Wu, F Wu: Study on simulation and mechanical properties of tunnel shield cutter head[J]. Computer Engineering and Applications, Vol. 11(2013), p. 248-251

[6] T.M Guan, C.H Liu, L Wu et al: Finite element analysis of shield cutter head in sandy cobble stratum[J]. Journal of Dalian Jiaotong University, Vol. 1(2015), p. 43-46

[7] Z.Y Ji: Finite element analysis of one type of EPB sheild cutting wheel[J]. Machinery Design \& Manufacture, Vol. 3(2012), p. 196-198 
[8] Y.M Xia, X.W Zhou, Y.J Liu et al: Finite element analysis of earth-pressure balance shield cutter-head[J]. Journal of Zhengzhou University(Engineering Science), Vol. 3(2009), p. 69-73

[9] Z Tong: The analysis and structural optimization of shield cutter[D]. Zheng Zhou: Zhengzhou University, 2012 